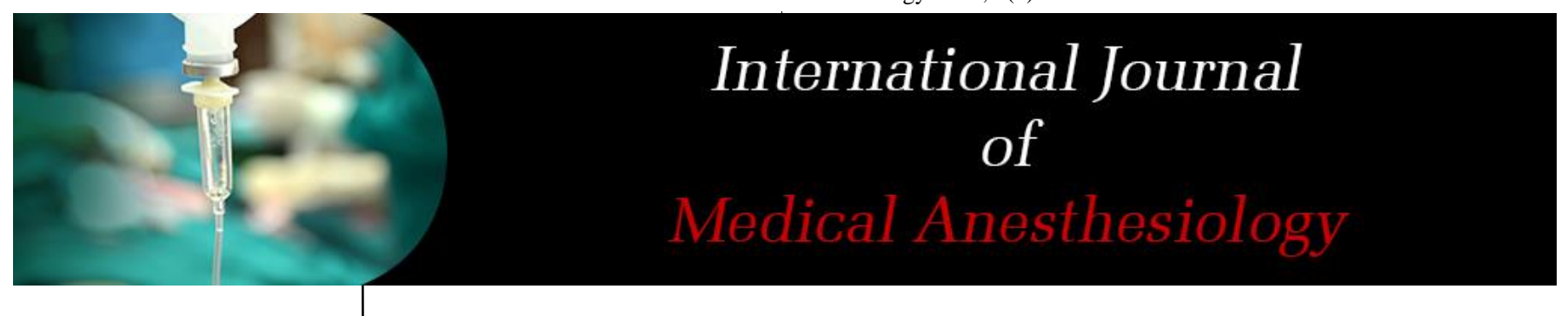

E-ISSN: 2664-3774

P-ISSN: 2664-3766

www.anesthesiologypaper.com

IJMA 2020; 3(3): 14-17

Received: 17-05-2020

Accepted: 18-06-2020

Prachi Deenbandhu Shelke

Department of

Anaesthesiology, DVVPF'S

Medical College, Ahmednagar,

Maharashtra, India

Sandeep Ramchandra Nale

Department of

Anaesthesiology, DVVPF'S

Medical College, Ahmednagar,

Maharashtra, India

Jinisha Babriya

Department of

Anaesthesiology, DVVPF'S

Medical College, Ahmednagar,

Maharashtra, India

Srishti Tiwari

Department of

Anaesthesiology, DVVPF'S

Medical College, Ahmednagar,

Maharashtra, India
Corresponding Author:

Sandeep Ramchandra Nale Department of

Anaesthesiology, DVVPF'S

Medical College, Ahmednagar,

Maharashtra, India

\section{A comparative study of epidural ropivacaine $0.2 \%$ with nalbuphine and ropivacaine $0.2 \%$ with fentanyl in unilateral total knee replacement surgeries}

\author{
Prachi Deenbandhu Shelke, Sandeep Ramchandra Nale, Jinisha Babriya \\ and Srishti Tiwari
}

DOI: https://doi.org/10.33545/26643766.2020.v3.i3a.140

\section{Abstract}

Background: Total knee replacement (TKR) is associated with intense early postoperative pain. Epidural opioids have unique advantages over conventional, intermittent IV/ IM administration, in that sooner in the postoperative period.

Materials and methods: This is prospective, double blind study where twenty patients in group A received Ropivacaine $0.2 \%$ with Nalbuphine and twenty patients in group B received Ropivacaine $0.2 \%$ with Fentanyl. Patients were assessed for hemodynamic changes, VAS scores, sedation scores and side effects.

Result: There was no statistically significant difference in the baseline parameters between the two groups. Rescue analgesics required in the first 24 hours of postoperative period in group A were significantly higher $(p<0.01)$ when compared with group B. Nalbuphine group had a good sedative action than Fentanyl group $(\mathrm{P}=0.04)$.

Conclusion: Fentanyl group is better in terms of quality of postoperative analgesia, lesser incidence of side-effects and patient satisfaction.

Keywords: Fentanyl, nalbuphine, ropivacaine, TKR

\section{Introduction}

Analgesia is one of the components of anaesthesia. It has now extended to relief of postoperative pain, chronic pain. Surgical patients require effective intra operative as well as post-operative pain control ${ }^{[1]}$.

The spinal cord has taken the centre stage in analgesia practice following the demonstration of analgesia with intrathecal Morphine by Yaksh and Rudy (1977) ${ }^{[2]}$. In 1947, Manuel Martinez Curbelo (1906-1962) was the first to describe placement of a lumbar epidural catheter $^{[3]}$.

Total knee replacement (TKR) is associated with intense early postoperative pain ${ }^{[4]}$. It is associated with high demands of analgesics. Proper management of pain after TKR is not just for the humane purpose of freeing patients from suffering. Rather, it is essential for successful TKR outcome in terms of improving patient satisfaction and quality of life and prevention of complications. Improving the pain management techniques and rehabilitation programs has a huge impact on postoperative outcome.

The use of epidural analgesia is the preferred technique of postoperative analgesia for unilateral total knee replacement ${ }^{[5]}$. A local anaesthetic -opioid combination provides superior analgesia during perioperative and postoperative period.

Epidural opioids have unique advantages over conventional, intermittent IV/IM administration, in that patients given epidural opioids have fewer respiratory complications and can be mobilized sooner in the postoperative period.

Nalbuphine, a derivative of 14-hydroxymorphine is a strong analgesic with mixed k agonist and $\mu$ antagonist properties. The analgesic potency of Nalbuphine has been found to be equal to Morphine but unlike Morphine, it exhibits a ceiling effect on respiratory depression. Nalbuphine has the potential to maintain or even enhance $\mu$-opioid based analgesia while simultaneously mitigating the $\mu$-opioid side effects ${ }^{[6]}$.

Fentanyl binds with stereospecific receptors at many sites within the central nervous system. It increases pain threshold, alters pain perception, inhibits ascending pain pathways. 
It is highly selective $\mu$ receptor agonist which appears to be specifically involved in the medication of analgesia. Opioids appear to exert their effects by increasing intracellular calcium concentration, which in turn increases $\mathrm{K}^{+}$ conductance and hyperpolarization of the excitable cell membranes decrease in membrane excitability that results may decrease both pre and post synaptic responses.

The aim of the present study was to compare the postoperative analgesic effect of Nalbuphine $20 \mathrm{mg}$ and Fentanyl $300 \mu \mathrm{g}$ as an adjuvant to continuous infusion of epidural Ropivacaine $0.2 \%$ in adult patients undergoing unilateral total knee replacement.

\section{Materials and methods}

Present study was done at DVVPF'S Medical College, Ahmednagar during 2018- 2019 on 40 patients in between age group of 20-60 years of ASA grade I and II undergoing unilateral total knee replacement after obtaining approval for the study from Institutional Ethics Committee. Written consent was obtained from all the patients included in the study.

\section{Inclusion criteria}

Patients posted for elective unilateral total knee replacement under ASA Grade I and II including both males and females in between age group of 20-60 years.

\section{Exclusion criteria}

1. Patient's refusal

2. Allergy to study drugs

3. Obese patients

4. Uncontrollable hypertension

5. Uncontrollable diabetes mellitus

6. Severe CVS abnormalities

7. Renal or hepatic failure

8. History of neurological surgeries

9. Spine deformities

10. Coagulation defects and patients those on anticoagulants.

Written Informed consent was obtained after explaining the procedure. All patients were subjected to pre-anaesthetic check up on the day before surgery to find out systemic illness complicating anaesthesia. On the day of surgery, the patients were shifted to the operation theatre and baseline vital hemodynamic parameters such as heart rate, noninvasive arterial blood pressure, oxygen saturation and ECG were noted. Intravenous line was secured with an $18 \mathrm{G}$ intravenous catheter and preloading was done with $500 \mathrm{ml}$ of Ringer's Lactate. Premedication was given with I.V. Ondansetron $4 \mathrm{mg}$. The patients were explained about the 10 point visual analogue of pain scale. Combined Spinal Anaesthesia (CSE) was decided to use for intraoperative and postoperative pain relief. After thorough aseptic precautions L1-L2 or L2- L3 space located and skin wheal raised by 26 gauge needle with $2 \%$ Lidocaine. Using a 18 gauge Huber point Tuohy needle epidural space was identified. With loss of resistance technique. Epidural catheter was inserted and aspirated to rule out subarachnoid or intravascular placement of the catheter. The placement was confirmed by
$3 \mathrm{ml}$ of 2\% lidocaine with adrenaline 1: 2,00,000 and fixed. Then, L3-L4 intervertebral space was identified and 25 gauge spinal needle was introduced. $3 \mathrm{ml}$ of injection Bupivacaine $0.5 \%(\mathrm{H})$ and injection Clonidine $15 \mu \mathrm{g}$ was injected intrathecally (in both groups). After one hour of induction of anaesthesia, $10 \mathrm{ml}$ of injection Ropivacaine $0.5 \%$ was given through epidural route (in both groups). All the patients in both the groups were given local knee infiltration of inj. Bupivacaine by operating surgeon. After surgery was over uneventfully, patient shifted to postoperative room and then after half an hour later study conducted postoperatively. The patients were randomly chosen into two groups.

Group A: Injection Ropivacaine $0.2 \%$ with injection Nalbuphine $0.13 \mathrm{mg}$ per $\mathrm{ml}$ at the rate of $6 \mathrm{ml}$ per hour

Group B: Injection Ropivacaine $0.2 \%$ with Injection Fentanyl $2 \mu \mathrm{g}$ per $\mathrm{ml}$ at the rate of $6 \mathrm{ml}$ per hour

\section{Ramsay Sedation Assessment Scale}

\begin{tabular}{|c|c|c|}
\hline \multirow{3}{*}{ Awake Levels } & Patient anxious or agitated or both & 1 \\
\cline { 2 - 3 } & Patient cooperative, oriented and tranquil & 2 \\
\cline { 2 - 3 } Asleep Levels & Patient responds to commands only & 3 \\
\hline & A brisk response to a light glabellar tap & 4 \\
\cline { 2 - 3 } & A sluggish response to a light glabellar tap & 5 \\
\cline { 2 - 3 } & No response & 6 \\
\hline
\end{tabular}

Patients were asked to mark a point scale on the 10-point visual analogue scale of pain according to the intensity of pain. The observation was done every 6 hourly. The pain relief is graded according to VAS as follows.

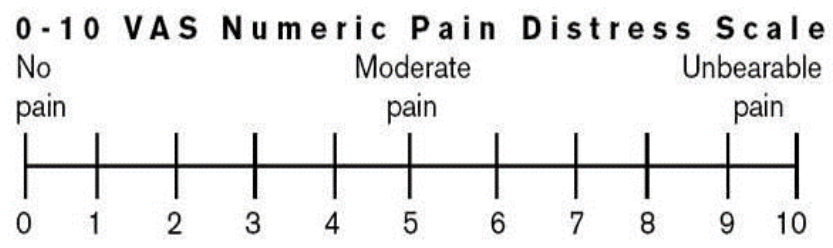

Rescue analgesia was given when VAS more than 4. The total number of rescue analgesics (inj. Paracetamol $1 \mathrm{gm} \mathrm{IV}$ and inj. Diclofenac $75 \mathrm{mg} \mathrm{IV}$ ) in the first 24 hours were noted down to assess the quality of analgesia.

The side effects due to opioids like nausea, vomiting, pruritis, urinary retention were noted down. The Statistical software namely Open Epi, Version 2.3 was used for the analysis of the data and Microsoft word and Excel have been used to generate tables. Results on continuous measurements were presented on Mean \pm SD and results on categorical measurements were presented in Number (\%). Significance was assessed at $5 \%$ level of significance. Significant $(\mathrm{P}$ value: $0.01<P<0.05)$ and highly significant (P value: $P<0.01$ ) were considered.

\section{Result}

There was statistically no significant difference between mean age, weight, gender and ASA grading in both groups (Table -1$)$. There was no statistically significant difference in the baseline parameters between the two groups (Table $2)$. 
Table 1: Comparison of demographic data in both groups

\begin{tabular}{|c|c|c|c|c|}
\hline \multicolumn{2}{|c|}{ Demographic parameters } & Group A (n=20) & Group B (n=20) & p value \\
\hline \multicolumn{2}{|c|}{ Age in years (Mean \pm S.D) } & $38.43 \pm 9.56$ & $39.06 \pm 9.83$ & 0.802 \\
\hline \multicolumn{2}{|c|}{ Weight in kg (Mean \pm S.D) } & $63.03 \pm 9.44$ & $62.7 \pm 9.59$ & 0.894 \\
\hline \multirow{2}{*}{ Sex } & Male & $22(73 \%)$ & $23(77 \%)$ & 0.72 \\
\cline { 2 - 5 } & Female & $8(27 \%)$ & $7(23 \%)$ & 0.72 \\
\hline \multirow{2}{*}{ ASA } & Grade I & $12(40 \%)$ & $12(40 \%)$ & 1.0 \\
\cline { 2 - 5 } & Grade II & $18(60 \%)$ & $18(60 \%)$ & 1.0 \\
\hline
\end{tabular}

Table 2: Comparison of baseline variables

\begin{tabular}{|c|c|c|c|}
\hline Baseline Parameters & Group A (Mean \pm S.D) & Group B (Mean \pm S.D) & p value \\
\hline Heart rate & $81.73 \pm 9.43$ & $81.23 \pm 8.98$ & 0.8333 \\
\hline Systolic blood pressure & $127.6 \pm 7.96$ & $125.76 \pm 7.49$ & 0.3603 \\
\hline Diastolic blood pressure & $83.23 \pm 5.36$ & $80.1 \pm 7.78$ & 0.07475 \\
\hline Mean arterial pressure & $98.1 \pm 5.1$ & $95.13 \pm 6.92$ & 0.06344 \\
\hline Respiratory rate & $15.8 \pm 0.80$ & $15.9 \pm 1.047$ & 0.7446 \\
\hline
\end{tabular}

Table 3: Comparison of VAS scores between the two groups

\begin{tabular}{|c|c|c|c|}
\hline \multicolumn{2}{|c|}{ Time } & \multicolumn{2}{c|}{ Vas Score } \\
\cline { 3 - 4 } & 0-4 & $\mathbf{5 - 1 0}$ \\
\hline \multirow{2}{*}{ 0-6 Hours } & Group A & $20(100 \%)$ & 0 \\
\cline { 2 - 4 } & Group B & $20(100 \%)$ & 0 \\
\hline \multirow{2}{*}{ 6-12 Hours } & Group A & $17(85 \%)$ & $3(15 \%)$ \\
\cline { 2 - 4 } & Group B & $18(90 \%)$ & $2(10 \%)$ \\
\hline \multirow{2}{*}{$12-18$ Hours } & Group A & $18(90 \%)$ & $2(10 \%)$ \\
\cline { 2 - 4 } & Group B & $18(90 \%)$ & $2(10 \%)$ \\
\hline \multirow{2}{*}{$18-24$ Hours } & Group A & $18(90 \%)$ & $2(10 \%)$ \\
\cline { 2 - 4 } & Group B & $19(95 \%)$ & $1(5 \%)$ \\
\hline
\end{tabular}

The pain scores were similar in both the groups in the first six hours of postoperative period. $15 \%$ of patients in group A had a pain score more than 4 (VAS 5) during 6-12 hours of postoperative period as compared to $2 \%$ in group B. Rescue analgesic (inj. Paracetamol 1 gm IV and inj. Diclofenac $75 \mathrm{mg}$ IV) was given when VAS score was more than 4. Number of rescue analgesics required in the first 24 hours of postoperative period in group A were significantly higher $(p<0.01)$ when compared with group B (Table -3$)$

Table 4: Comparison of sedation score between two groups

\begin{tabular}{|c|c|c|c|}
\hline \multicolumn{2}{|c|}{ Time } & \multicolumn{2}{c|}{ Sedation score } \\
\cline { 3 - 4 } & G-3 & $\mathbf{3 - 4}$ \\
\hline \multirow{2}{*}{$0-6$ Hours } & Group A & $2(10 \%)$ & $18(90 \%)$ \\
\cline { 2 - 4 } & Group B & $17(85 \%)$ & $3(15 \%)$ \\
\hline \multirow{2}{*}{$6-12$ Hours } & Group A & $3(15 \%)$ & $17(85 \%)$ \\
\cline { 2 - 4 } & Group B & $18(90 \%)$ & $2(10 \%)$ \\
\hline \multirow{2}{*}{$12-18$ Hours } & Group A & $4(20 \%)$ & $16(80 \%)$ \\
\cline { 2 - 4 } & Group B & $18(90 \%)$ & $2(10 \%)$ \\
\hline \multirow{2}{*}{$18-24$ Hours } & Group A & $5(25 \%)$ & $15(75 \%)$ \\
\cline { 2 - 4 } & Group B & $19(95 \%)$ & $1(5 \%)$ \\
\hline
\end{tabular}

There was statistically difference in sedation score (p value 0.04 ) between the two groups (Table - 4). Nalbuphine group had a good sedative action than Fentanyl group.

Table 5: Comparison of side effects in between both the groups

\begin{tabular}{|c|c|c|c|c|c|}
\hline \multirow{2}{*}{ Side Effects } & \multicolumn{2}{|c|}{ Group -A } & \multicolumn{2}{c|}{ Group -B } & p value \\
\cline { 2 - 6 } & $\mathbf{N}$ & $\mathbf{\%}$ & $\mathbf{n}$ & $\mathbf{\%}$ & \\
\hline Nausea and vomitting & 3 & $10 \%$ & 1 & $3.3 \%$ & 0.3 \\
\hline Respiratory depression & 4 & $13.3 \%$ & - & - & 0.2 \\
\hline Urinary retention & - & - & - & - & - \\
\hline Pruritis & 3 & $10 \%$ & - & - & 0.7 \\
\hline Hypotension & 3 & $10 \%$ & 2 & $6.6 \%$ & 0.63 \\
\hline Bradycardia & 2 & $6.6 \%$ & 1 & $3.3 \%$ & 0.5 \\
\hline Shivering & 2 & $6.6 \%$ & 1 & $3.3 \%$ & 0.5 \\
\hline
\end{tabular}

Comparison of side effects in between both the groups was statistically insignificant. All the side effects were treated immediately (Table-5).

\section{Discussion}

Regional techniques, such as spinal and epidural anaesthesia may offer advantages over general anaesthesia including reduced stress response to surgery and analgesia, which generally extends into the postoperative period ${ }^{[7,8]}$. The CSE technique gives new dimension to the management of postoperative pain. Any mode of postoperative analgesia must meet three basic criteria: It must be effective, safe and feasible. In the majority of the patients after surgery, pain is not fully relieved with intravenous route of drugs ${ }^{[9]}$. The discovery of opioid receptors in the brain and spinal cord started a new era in the field of postoperative analgesia. Ropivacaine is a local anaesthetic, which belongs to the amide group of anaesthetic agents that has been widely used for local infiltration, peripheral nerve blocks, spinal and epidural anaesthesia. Various adjuvants have been added to the local anaesthetics to minimize the side effects of local anaesthetics and prolong the duration of intraoperative and postoperative analgesia ${ }^{[10]}$.

In present study Demographic data comparing age, sex, weight shows no statistically significant difference among both the groups.

There was difference in sedation scores between two groups. Nalbuphine group had more sedative action than Fentanyl group. There was statistically no significant difference in the baseline parameters between the two groups.

In this study, the duration of postoperative analgesia in patients with the addition of Fentanyl was more prolonged as compared to Nalbuphine. Number of rescue analgesics required in the first 24 hours of postoperative period in group A were significantly higher $(p<0.01)$ when compared with group B. Nalbuphine is an opioid having agonistic action at kappa and antagonist activity at $\mu$ opioid receptors and provided reasonably potent analgesia in visceral nociception ${ }^{[11]}$ was found to improve the quality of postoperative analgesia ${ }^{[12]}$ with fewer side effects. Verma $e t$ al. showed that postoperative analgesia was significantly improved by the addition of nalbuphine ${ }^{[13]}$.

In this study, there was statistically no difference in side effects between two groups. 


\section{Conclusion}

This prospective, randomised, double blind study, where in epidural Nalbuphine $0.13 \mathrm{mg}$ per $\mathrm{ml}$ with $0.2 \%$ Ropivacaine at $6 \mathrm{ml}$ per hour and epidural Fentanyl $2 \mu \mathrm{g}$ per $\mathrm{kg}$ with $0.2 \%$ Ropivacaine at $6 \mathrm{ml}$ per hour in unilateral total knee replacement concludes that both Nalbuphine and Fentanyl are effective for postoperative analgesia when used epidurally in patients undergoing unilateral total knee replacement surgery. However, Fentanyl group is better in terms of better quality of postoperative surgical analgesia, lesser incidence of side-effects and complications e.g. nausea, vomiting and respiratory depression. Fentanyl group has better patient satisfaction compared to Nalbuphine group.

\section{References}

1. Epidural nalbuphine for postoperative analgesia in orthopedic surgery Veena Chatrath, Joginder Pal Attri, Anju Bala, Ranjana Khetarpal, Deepti Ahuja, and Sawinder Kaur.

2. Yaksh TL, Rudy TA. Studies on the direct spinal action of narcotics in the production of analgesia in the rat. Joumal of Pharmacology \& Experimental Therapeutics. 1977; 202:411-428.

3. Martinez Curbelo M. Continuous peridural segmental anesthesia by means of a ureteral catheter. Curr Res Anesth Analg. 1949; 28(1):13-23.

4. Wang H, Boctor B, Verner J. The effect of singleinjection femoral nerve block on rehabilitation and length of hospital stay after total knee replacement. Reg Anesth Pain Med. 2002; 27:139-44. | Article | PubMed

5. Benhamou D, Berti M, Brodner G, De Andres J, Draisci G, Moreno-Azcoita M et al. Postoperative Analgesic THerapy Observational Survey (Pathos): a practice pattern study in 7 central/southern European countries. Pain. 2008; 136:134-41. | Article | PubMed

6. Gunion MW, Marchionne AM, Anderson TM. Use of the mixed agonist-antagonist nalbuphine in opiod based analgesia. Acute Pain. 2004; 6:29-39. [Google Scholar]

7. Andres J, Valia JC, Gill A, Bolinches R. Predictor of patient satisfaction with regional anaesthesia. Reg Anesth. 1995; 20:198-505. [PubMed] [Google Scholar]

8. Roussel JR, Heindel L. Effects of intrathecal fentanyl on duration of bupivacaine spinal blockade for outpatient knee arthroscopy. AANA J. 1999; 67:33743. [PubMed] [Google Scholar]

9. Moote C. Technique for postoperative pain management in the adult. Can J Anaesth. 1993; 63:18995. [Google Scholar]

10. Bernards CM. Recent insights into the pharmacokinetics of spinal opioids and the relevance to opioid selection. Curr Opin Anaesthesiol. 2004; 17:4417. [PubMed] [Google Scholar]

11. Schmauss C, Doherty C, Yaksh TL. The analgetic effects of an intrathecally administered partial opiate agonist, nalbuphine hydrochloride. Eur J Pharmacol. 1982; 86:1-7. [PubMed] [Google Scholar]

12. Tiwari AK, Tomar GS, Agrawal J. Intrathecal Bupivacaine in comparison with a combination of nalbuphine and bupivacaine for subarachnoid block: A randomised prospective double blind clinical study. Am J Ther. 2013; 20:592-5. [PubMed] [Google Scholar]

13. Verma D, Naithani U, Jain DC, Singh A. Post-operative analgesic efficacy of intrathecal tramadol versus nalbuphine added to bupivacaine in spinal anaesthesia for lower limb orthopaedic surgery. J Evol Med Dent Sci. 2013; 2:6196-206. [Google Scholar] 